\title{
The Role and Impact of Supplemental Instruction in Accelerated Developmental Math Courses
}

Tanu K. Altomare, University of Houston-Downtown

Ashley N. Moreno-Gongora, University of Houston-Downtown

\section{ABSTRACT}

A difficult issue for tutoring programs is low participation, especially at commuter campuses. At the University of Houston-Downtown, this problem seems particularly acute for developmental education (DE) courses. This paper describes the Supplemental Instruction (SI) program at the University of Houston-Downtown (UHD) with focus on the role of the SI Leader in accelerated DE math courses. A study was conducted between Fall 2015 and Spring 2017 to evaluate differences in student performance in two courses between sections that were staffed with an SI Leader and those that had no assistance from the SI program. The study found statistically significant differences in grade performance between SI session participants and non-SI participants. The study also found that students passed at a higher rate in accelerated Intermediate Algebra as compared to traditional biweekly sections. Finally, students passed at a higher rate in accelerated sections that were staffed with an SI Leader compared to accelerated sections without an SI Leader.

upplemental Instruction (SI) is an internationally recognized postsecondary academic support program that aims to improve student performance in high-attrition courses through the use of collaborative learning techniques (Hodges \& White, 2001). In the SI model, SI Leaders attend their assigned section and serve as model students; they take notes, ask questions, and are attentive during lecture. Outside of class, the SI Leaders facilitate weekly, informal study sessions that focus on course-content mastery through group learning. These SI study sessions begin the first week of class and end when students take their final exams. SI Leaders assist students with organizing content and developing effective study techniques with the goal of driving students to become independent, confident learners. The SI method is designed to reduce the remedial stigma that students associate with seeking academic assistance (Arendale, 1994).

The University of Houston-Downtown (UHD) has had an active SI program since 2001. UHD, located in Houston, Texas, is a minority-serving commuter institution with an approximate student population of 14,000 . The average student age at UHD is 27 years and the average faculty-student ratio in classrooms is 20:1. As of Fall 2016, 51\% of students were designated as part-time (UHD, 2017).

The SI Leader serves as an extension of the students and aims to "bridge the gap" between lecture content and student comprehension. The primary role of any SI Leader in the classroom is to serve as a model student, which includes arriving to class on time, actively participating in activities, and asking questions during class. In addition, the SI Leader conducts study sessions outside of class that address difficult topics and help students learn effective study techniques.

Although research has shown the value of tutoring and other support services to students at-risk to succeed (Laskey \& Hetzel, 2011), this effect is minimized when students have low or inconsistent attendance to tutoring or when they start seeking academic support late in the semester (Hodges \& White, 2001). At UHD, the SI program aimed to address this issue by providing more active academic support in the classroom. We hypothesized that providing academic support during class time would positively impact student grade performance, regardless of whether students attend out-of-class tutoring sessions. The objective of this study was to determine the impact on math student grade performance in two accelerated developmental education (DE) courses using a modified version of the traditional Supplemental Instruction model.

\section{Methods}

The UHD SI program offers assistance for five subjects (mathematics, history, chemistry, biology, and physics) and currently supports 57 sections. Priority is given to $D E$ and other gateway courses based on low passing rates and departmental goals. UHD SI Leaders are current undergraduate students who have at least a 3.0 cumulative GPA and have made a $\mathrm{B}$ or higher in the class they are assigned. 


\section{Study Population}

This study was conducted between Fall 2015 and Spring 2017. SI Leaders assisted with two accelerated DE math courses: Beginning Algebra and Intermediate Algebra. There are two combinations of corequisite sequences offered at UHD: students register for Beginning Algebra in the first eight weeks and move into either Intermediate Algebra or Contemporary Math (a college-level course) for the second eight weeks; or students register for Intermediate Algebra in the first eight weeks and move into College Algebra in the second half of the semester (Figure 1). For the duration of this study, the probability that a student would enroll in an SI-assisted section was randomized. Students and advisors were not aware prior to the first day of class which sections had SI support. Additionally, SI-assisted sections and non-SI sections were priced the same.

1st 8 Weeks
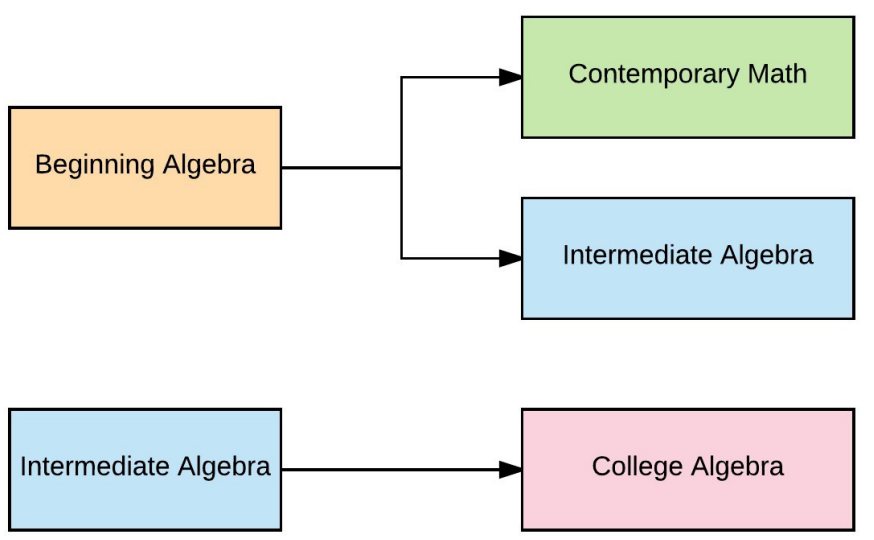

Figure 1. Two sequences of DE corequisite courses offered at UHD. Top sequence represents course flow for students placed in Beginning Algebra. Bottom sequence represents course flow for students placed in Intermediate Algebra. Diagram created in Lucidchart (www.lucidchart.com).

\section{Format}

In these DE course sequences, both classes and SI sessions were held four days a week (MondayThursday). Lectures were one hour and fifteen minutes in length, and SI sessions were sixty minutes in length. SI sessions occurred immediately before class, immediately after class, or later in the afternoon. Sessions were scheduled based on the majority availability of the students, determined via paper or oral survey on the first day of class. In class, the teaching approach was structured around problem-based learning. Most lectures involved problem sets, which students attempted individually, in pairs, or in groups. During this time, the SI Leader assisted by moving around to different groups and facilitating discussion. SI Leaders also met with students one-on-one during class time to offer individual feedback and assistance.

\section{Results}

Results were obtained using student grade data from Banner ${ }^{\circledR}$ by Ellucian and SI attendancedata collected through TutorTrac by Redrock Software. The student pass rates for Beginning Algebra and Intermediate Algebra between SI participants and non-SI participants are summarized in Tables 1 and 2. SI participants are defined as students who attended at least one $\mathrm{SI}$ session during the target semester. Pass rate includes grades of $A, B$, or $C$.

Baseline pass rates for students in Beginning and Intermediate Algebra were reported for Fall 2013 as $54 \%$ and $49 \%$, respectively. Table 3 summarizes the pass rate for students in Beginning Algebra in sections that were assisted by an SI Leader versus students in accelerated sections without an SI Leader. In Fall 2015, 37\% of Beginning Algebra students who were assigned an SI Leader attended at least one out-of-class SI sessions during the semester. Of this percentage, $86 \%$ of students received a C-or-higher final grade after the 8 -week course. The pass rate for the section that received SI assistance was $82 \%$, compared to a $55 \%$ pass rate for students in an accelerated Beginning Algebra course that did not have an assigned SI Leader (Table 3).

For Intermediate Algebra, UHD offered traditional biweekly sections in conjunction with accelerated corequisite sections for the duration of the study. The pass rates for students in SI-assisted accelerated sections, accelerated sections without an SI Leader, and traditional biweekly sections (control group) are summarized in Table 4. In Spring 2016 and Spring 2017, all accelerated sections of Intermediate Algebra received assistance from an SI Leader.

In Spring 2016, 58\% of Beginning Algebra students who were assigned an SI Leader attended at least one out-of-class SI sessions during the semester. The pass rate for these students was $91 \%$, compared to a $25 \%$ pass rate for non-attendees. In Fall 2016 and Spring 2017, the attendance rate to SI sessions for Beginning Algebra students was $29 \%$ and $17 \%$, respectively, and the pass rate for these participants was $94 \%$ and $67 \%$, respectively (Table 1). A chi-square analysis of the aggregate data across four semesters yielded a statistically significant difference in pass rates between SI participants and non-participants in Beginning Algebra ( $p=0.012$ ).

Data for Intermediate Algebra students includes students in the second eight weeks of sequence $A$ and the first eight weeks of sequence $B$ (Figure 1). In Fall 2015, 29\% of students in an SI-assisted accelerated section attended at least one outof-class $\mathrm{SI}$ session. These students passed at a rate of $94 \%$, compared to $64 \%$ pass rate for non-attendees. In Spring 2016, 35\% of Intermediate Algebra students who were assigned an SI Leader attended at least one out-of-class SI sessions during the semester. The pass rate for these students was $100 \%$, compared to a $64 \%$ 
pass rate for non-attendees. In Fall 2016 and Spring 2017, the attendance rate to SI sessions for Intermediate Algebra students was $32 \%$ and $25 \%$, respectively, and the pass rate for these participants was $89 \%$ and $100 \%$, respectively (Table 2 ). A chi-square analysis of the aggregate data across four semesters yielded a statistically significant difference in pass rates between SI participants and non-participants in Intermediate Algebra ( $p=0.009)$.

In all semesters included in this study, UHD offered traditional biweekly sections of Intermediate Algebra in conjunction with accelerated sections. These sections met twice a week for 16 weeks. Table 4 compares the pass rates for students who were enrolled in accelerated sections that had SI Leader assistance, accelerated sections without SI Leader assistance, and traditional biweekly sections (control sections). In Spring 2016 and 2017, all accelerated Intermediate Algebra sections received SI assistance. In all cases, the accelerated sections with SI assistance outperformed accelerated sections without assistance, and students from accelerated sections outperformed students enrolled in traditional biweekly sections (Table 4).

Table 1

Number and Percentage of Students who Passed With an $A, B$, or C in Beginning Algebra Between Fall 2015 and Spring 2017 Categorized by SI Participation

\begin{tabular}{|c|c|c|c|c|}
\hline & $\begin{array}{l}\frac{\text { Total }}{\text { Number }} \\
\text { of SI Par- } \\
\underline{\text { ticipants }}\end{array}$ & $\begin{array}{l}\frac{\text { Number }}{\text { of SI Par- }} \\
\text { ticipants } \\
\text { With } \\
\text { Passing } \\
\text { Grade (\%) }\end{array}$ & $\begin{array}{l}\frac{\text { Number }}{\text { of Non-SI }} \\
\frac{\text { Partici- }}{\text { pants }}\end{array}$ & $\begin{array}{l}\frac{\text { Number }}{\text { of Non-SI }} \\
\frac{\text { Participants }}{\text { With Passing }} \\
\text { Grade }(\%)\end{array}$ \\
\hline $\begin{array}{l}\text { Fall } \\
2015\end{array}$ & 14 & $12(86 \%)$ & 24 & 19 (79\%) \\
\hline $\begin{array}{l}\text { Spring } \\
2016\end{array}$ & 11 & 10 (91\%) & 8 & $2(25 \%)$ \\
\hline $\begin{array}{l}\text { Fall } \\
2016\end{array}$ & 17 & 16 (94\%) & 41 & 31 (76\%) \\
\hline $\begin{array}{l}\text { Spring } \\
2017\end{array}$ & 3 & 2 (67\%) & 15 & $9(60 \%)$ \\
\hline Total & 45 & 40 (89\%) & 88 & 61 (69\%) \\
\hline
\end{tabular}

Note: Baseline pass rate for baseline semester (Fall 2013) was 54\%. An SI participant label was given to a student who attended at least one session for Beginning Algebra during the course of the semester.

Chi-square value: $\chi=6.2415(\rho=0.012)$
Table 2

Number and Percentage of Students who Passed With an $A, B$, or $C$ in Intermediate Algebra Between Fall 2015 and Spring 2017 Categorized by SI Participation

\begin{tabular}{|c|c|c|c|c|}
\hline & $\frac{\frac{N \text { Value }}{\text { of SI Par- }}}{\underline{\text { ticipants }}}$ & $\begin{array}{l}\frac{\text { Number }}{\text { of SI Par- }} \\
\frac{\text { ticipants }}{\text { With }} \\
\frac{\text { Passing }}{\text { Grade (\%) }}\end{array}$ & $\frac{\underline{\mathrm{N} \text { Value of }}}{\text { non-SI Par- }}$ & $\begin{array}{l}\frac{\text { Number }}{\text { of Non-SI }} \\
\text { Partici- } \\
\text { pants With } \\
\text { Passing } \\
\text { Grade (\%) }\end{array}$ \\
\hline $\begin{array}{l}\text { Fall } \\
2015\end{array}$ & 16 & 15 (94\%) & 41 & 36 (88\%) \\
\hline $\begin{array}{l}\text { Spring } \\
2016\end{array}$ & 6 & $6(100 \%)$ & 11 & 7 (64\%) \\
\hline $\begin{array}{l}\text { Fall } \\
2016\end{array}$ & 18 & 16 (89\%) & 39 & $24(62 \%)$ \\
\hline $\begin{array}{l}\text { Spring } \\
2017\end{array}$ & 2 & 2 (100\%) & 6 & $4(67 \%)$ \\
\hline Total & 42 & 39 (93\%) & 97 & 71 (73\%) \\
\hline
\end{tabular}

Note: Baseline pass rate for baseline semester (Fall 2013) was 49\%. An SI participant label was given to a student who attended at least one session for Intermediate Algebra during the course of the semester. Participants are included from both sequences.

Chi-square value: $\chi=6.8623(\rho=0.009)$ 
Table 3

Percentage of Students who Passed With an $A, B$, or $C$ in Beginning Algebra Between Fall 2015 and Spring 2017 Categorized by SI Designation

\begin{tabular}{|c|c|c|c|c|}
\hline & $\begin{array}{l}\text { SI Accelerat- } \\
\frac{\text { ed Section }}{(\mathrm{N})}\end{array}$ & $\frac{\frac{\text { Num- }}{\text { ber }(\%)}}{\frac{\text { Passed }}{\text { from SI }}}$ & $\frac{\frac{\text { Non-SI }}{\text { Accelerated }}}{\text { Section (N) }}$ & $\begin{array}{l}\frac{\text { Number }}{\text { (\%) Passed }} \\
\text { from non- } \\
\text { SI Section }\end{array}$ \\
\hline Fall 2015 & 38 & 31 (82\%) & 22 & $12(55 \%)$ \\
\hline $\begin{array}{l}\text { Spring } \\
2016\end{array}$ & NA & NA & NA & NA \\
\hline Fall 2016 & NA & NA & NA & NA \\
\hline $\begin{array}{l}\text { Spring } \\
2017\end{array}$ & NA & NA & NA & NA \\
\hline $\begin{array}{l}\text { Note: N/ } \\
\text { sistance } \\
\text { section t } \\
\text { SI Leade }\end{array}$ & $\begin{array}{l}=\text { All accele } \\
\text { this seme } \\
\text { at receivec }\end{array}$ & $\begin{array}{l}\text { ated se } \\
\text { ter. SI s } \\
\text { consist }\end{array}$ & $\begin{array}{l}\text { ions receiv } \\
\text { tion is defi } \\
\text { t assistanc }\end{array}$ & $\begin{array}{l}\text { d SI as- } \\
\text { ed as the } \\
\text { from an }\end{array}$ \\
\hline
\end{tabular}

Table 4

Percentage of Students who Passed With an A, B, or C in Intermediate Algebra Between Fall 2015 and Spring 2017 Categorized by SI Designation

\begin{tabular}{|c|c|c|c|c|c|c|}
\hline & $\begin{array}{l}\text { SI Accelerated } \\
\underline{\text { Section }(N)}\end{array}$ & $\begin{array}{l}\frac{\text { Number }(\%)}{\text { Passed From }} \\
\underline{\text { SI Accelerated }} \\
\underline{\text { Section }}\end{array}$ & $\frac{\frac{\text { Non-SI }}{\text { Accelerated }}}{\text { Section (N) }}$ & $\begin{array}{l}\frac{\text { Number }}{(\%) \text { Passed }} \\
\text { from Non-SI } \\
\text { Accelerated } \\
\text { Section }\end{array}$ & $\frac{\frac{\text { Control }}{\text { Sections }}}{\text { (N) }}$ & $\begin{array}{l}\frac{\text { Number }}{(\%) \text { Passed }} \\
\frac{\text { From }}{\text { Control }} \\
\text { Sections }\end{array}$ \\
\hline Fall 2015 & 57 & 51 (89\%) & 27 & 21 (78\%) & 127 & 76 (60\%) \\
\hline Spring 2016 & 17 & $13(76 \%)$ & NA & NA & 38 & $22(58 \%)$ \\
\hline Fall 2016 & 57 & 40 (70\%) & 40 & $25(63 \%)$ & 100 & 64 (64\%) \\
\hline Spring 2017 & 8 & $6(75 \%)$ & NA & NA & 40 & 20 (50\%) \\
\hline
\end{tabular}

Note: NA = All accelerated sections received SI assistance in this semester. Control group was defined as all full term 16-week sections that did not receive any assistance by an SI Leader. 


\section{Discussion}

While studies have found SI to benefit students-especially students deemed at-risk - motivating students to participate in academic support has been an ongoing issue at many institutions (Hodges \& White, 2001). In this study, students who tested below college-ready in math were placed in accelerated Beginning Algebra or Intermediate Algebra for the first eight weeks of the semester. An SI Leader was staffed in at least one section for the four semesters of the study period. During this study period, students were encouraged by the SI Leader and faculty instructor to attend SI sessions, but did not receive extra incentive to attend sessions. Additionally, the SI Leader regularly interacted and assisted students during daily problem-solving exercises.

After Fall 2015, the number of incoming students testing at Beginning Algebra level significantly declined; as a result, only one accelerated section of this course was offered for subsequent semesters. Due to the substantial difference in pass rates between the SI-assisted section and non-SI section, funding prioritized SI assistance for this course. All subsequent accelerated Beginning Algebra sections after Fall 2015 received assistance from an SI Leader.

Overall, the results of this study demonstrated significant improvements in grade performance for students that took advantage of out-of-class SI sessions, as well as for students who only had in-class interaction with an SI Leader. In all semesters included in this study, students in SI-assisted sections performed better than students without an SI Leader. Furthermore, students who participated in out-of-class SI study sessions passed at a higher rate compared to non-attendees. Comparisons in Table 4 between two accelerated sections and between accelerated and non-accelerated sections show that, overall, acceleration is a useful course-design model to improve student performance at UHD; however, grade improvement can be augmented further with in-class peer academic support.

The success of SI is highly dependent on the interaction and rapport the students build with the SI Leader inside the classroom. In an accelerated classroom, the SI Leader can meet with the students four days a week and interact with them regularly during the problem-solving segments of the lecture. This constant exposure allows the SI Leader to build rapport with the students earlier than a traditional biweekly course. The results of this study suggest that classroom interaction is key in building a strong "near-peer" relationship between the SI Leader and the student. In courses where the SI Leader has active interaction with students, we have observed higher attendance rates to SI study sessions and a wider gap in overall pass rate between participants and non-participants. This trend is present not only in DE courses, but also in college-level courses at UHD.

Student attendance and participation in SI sessions can vary significantly by semester. For Beginning Algebra, attendance ranged from 17-58\%, with an average of $35 \%$ attendance. For Intermediate Algebra, attendance ranged from $25-35 \%$, with an average of $30 \%$ attendance. This is considered low if compared to other Sl-assisted courses, where student attendance ranges from $40-60 \%$. To counteract low attendance to out-of-class sessions, $\mathrm{SI}$ Leaders facilitated student learning in the classroom itself. Thus, any possible issues related to lack of motivation in seeking out academic support was minimized. This embedded model might be especially useful at institutions with limited academic support budgets. It is cost-effective to bring the assistance to where the students are; in addition, the students may be more likely to be open to receiving support if it is provided concurrently with their learning experience.

\section{Study Limitations and Recommendations for Practice}

The populations included in the scope of this study were relatively small. The size of the population studied can affect statistical power, which may have reduced our ability to identify differences that can exist between these two groups. In addition, there was not a traditional biweekly Beginning Algebra section to use as a control for comparison. Without a comparison group, the impact of SI on student performance can be difficult to determine. For future studies, we will focus on comparisons in Intermediate Algebra, for which there are traditional biweekly sections, in order to better understand the impact of SI and acceleration as separate variables.

Faculty instruction also plays a role in student performance; research has shown an increase in student performance in conjunction with more faculty-student interaction (Kuh, 2003). Accelerated courses at UHD met four times a week in this study and performed better in comparison to the traditional biweekly sections (Table 4). Therefore, some limitations regarding faculty/student relationships can be eliminated. Studies have also shown that student performance improves when students are content with their faculty member (Lundberg \& Schreiner, 2004). 
While the students may be interacting with their faculty member four times a week, the differences in pedagogical methods also play a role in student performance and were not taken into account for this study. For example, instructors in biweekly sections may have chosen a traditional lecture-based teaching model to relay course content to students versus the student-centered model used in the accelerated, SI-assisted sections in this study. Faculty who foster a supported learning environment by integrating collaborative learning and higher order type activities into their classroom dramatically increase student engagement (Umbach \& Wawrzynski, 2005). Differences in teaching models may have contributed to the differences seen in student grade performance. These factors were not addressed in this study; however, they are currently being investigated by other departments. Universities should seek to find the best practices that foster quality student-faculty relationships and engagement for their unique populations.

Self-selection in SI can occur in two ways. Highly motivated students may be more likely to enroll in a section if they know they will receive in-class SI assistance (Kahan, Rehal, \& Cro, 2015). At UHD, sections that will be staffed with an SI Leader are not revealed to the students or their advisors during enrollment; moreover, all courses are priced at the same rate, regardless of SI presence. The probability that a student will enroll in an SI-assisted section was randomized for the duration of this study, which largely eliminated self-selection bias for this case.

The second form of self-selection bias can occur if $\mathrm{SI}$ sessions are predominantly attended by highly-motivated students. Multiple studies have shown that students placed in DE courses may display lower levels of self-regulated learning behaviors. (Ley \& Young, 1998) and may perceive themselves to have significantly lower levels of self-efficacy compared to college-ready students (Koch, Slate, \& Moore, 2012). This perception seems to be especially prevalent in freshman math students (Hall \& Ponton, 2005). This study was limited to students in two DE math courses. We concluded that the percentage of highly motivated students in our study cohort was not significantly large enough to cause bias in the data.

\section{Conclusion}

New modes of instruction for DE postsecondary education are ongoing topics at many institutions. Fast track courses, such as the accelerated model in this study, as well as other frameworks, have been introduced as methods to help students move through remedial courses faster in order to increase the likelihood of retention and completion (Rutschow \& Schneider, 2011). Adding SI as an enhancement to course acceleration may yield better improvements in student performance and completion than using the model on its own. However, these improvements are best achieved when the SI Leader can interact with students in the classroom.

For future studies, we would like to evaluate data on grade performance in college-level math courses for students enrolled in an accelerated sequence versus students enrolled in a 16-week biweekly section. We also aim to follow the students who participated in this study to assess any longterm effects on retention and graduation as a result of SI assistance. Lastly, we would like to address the possible impact of faculty instruction on the performance of DE students at UHD.

\section{References}

Arendale, D. R. (1994). Understanding the supplemental instruction model. In D. C. Martin \& D. R. Arendale (Eds.), New Directions for Teaching and Learning: Supplemental Instruction: Increasing achievement and retention (pp. 1121). San Francisco, CA. Jossey-Bass.

Hall, J. M., \& Ponton, M. K. (2005). Mathematics self-efficacy of college freshman. Journal of Developmental Education, 28(3), 26-32.

Hodges, R., \& White, W. G. (2001). Encouraging highrisk student participation in tutoring and supplemental instruction. Journal of Developmental Education, 24(3), 2-10.

Kahan, B. C., Rehal, S., \& Cro, S. (2015). Risk of selection bias in randomized trials. Trials, 16, 405412.

Koch, B., Slate J. R., \& Moore, G. (2012). Perceptions of students in developmental classes. Community College Enterprise, 18(2), 62-82.

Kuh, G. D. (2003). What we're learning about student engagement from NSSE: Benchmarks for effective educational practices. Change: The Magazine of Higher Learning, 35(2), 24-32.

Laskey, M. L., \& Hetzel, C. J. (2011). Investigating factors related to retention of at-risk college students. Learning Assistance Review, 16(1), 3143.

Ley, K., \& Young, D. B. (1998). Self-regulation behaviors in underprepared (developmental) and regular admission college students. Contemporary Educational Psychology, 23(1), 42-64.

Lundberg, C. A., \& Schreiner, L. A. (2004). Quality and frequency of faculty-student interaction as predictors of learning: An analysis by student race/ ethnicity. Journal of College of Student Development, 45(5), 549-565.

Rutschow, E. Z., \& Schneider, E. (2011). Unlocking the gate: What we know about improving developmental education. New York, NY: MDRC.

Umbach, P.D., \& Wawrzynski, M. R. (2005). Faculty do matter: the role of college faculty in student learning and engagement. Research in Higher Education, 46(2), 153-184.

University of Houston-Downtown. (2017). Fact book. Houston, Texas: Office of Institutional Research. 